Hamburger Klopstock-Ausgabe 



\section{FRIEDRICH GOTTLIEB KLOPSTOCK}

WERKE UND BRIEFE

HISTORISCH-KRITISCHE AUSGABE

Begründet von Adolf Beck, Karl Ludwig Schneider und

Hermann Tiemann

Herausgegeben von Horst Gronemeyer,

Elisabeth Höpker-Herberg, Klaus Hurlebusch und Rose-Maria Hurlebusch

Verlag Walter de Gruyter in Berlin und New York

Abteilung Briefe: V I 



\section{Friedrich \\ Gottlieb Klopstock Briefe \\ I767 - I772}

Herausgegeben von

Klaus Hurlebusch

Band I: Text

Walter de Gruyter

Berlin, New York 1989

$W$
$0 E$
$G$ 
